\title{
Experiences in the Application of Alternative Delivery Mode (ADM) Learning Resources during the Pandemic Period
}

\section{Edward Castro Jimenez ${ }^{*}$}

Department of Education, Schools Division of City of Meycauayan, Bulacan 3020, Philippines

\begin{tabular}{|c|c|c|}
\hline Received: 18.10 .2021 & - Accepted: 11.11.2021 & - $\quad$ Published: 18.12.2021 \\
\hline
\end{tabular}

\begin{abstract}
This study reflected the experiences and perspectives of Learning Resource Coordinators during the COVID-19 pandemic in the application of the Alternative Delivery Mode (ADM) Learning Resources in the Schools Division Office, Central Luzon, Philippines. The study employed a narrative-inquiry approach to gather pertinent experiences from a group of participants. The participants were 10 Learning Resource Coordinators selected using a cluster sampling technique. The proponent used a research-made questionnaire to gather data. From the narratives of the informants, the proponent developed a unique thematic analysis. Based on the thematic analysis of the narrative inquiry, the informants revealed different perspectives and experiences, which state the different challenges met and the practical solutions in the delivery and correcting errors in the ADM Learning Resources. Based on the aforementioned findings, the proponent of this research provided some essential recommendations, in particular, an intervention program for this particular subject matter for learning resource coordinators and other significant key players of the Alternative Delivery Mode (ADM) implementors.
\end{abstract}

Keywords: Delivery Mode (ADM), Learning Resource Coordinator, Learning Resource, Narrative Inquiry, Pandemic Period

\section{INTRODUCTION}

Learning Resources (LRs) are prominent materials necessary for every learner. The use of different learning resources through printed and digitized learning resources helps the promotion of mastery of learning competencies offered by the Department of Education (DepEd). These learning resources are vital sources of information, ideas, and skills of every learner to master the competencies being offered and to be used as instruments in today's new normal in education in this time of the novel corona virus disease 2019 (COVID-19) pandemic. The current situation prompted the change in perspective of every educator to mobilize the different platforms and modalities for the education process to resume learning. According to Libbrecht (2015), learning resources were created to represent digital units of exchangeable materials that teachers and learners can pull from in order to support the learning activities. The facets of learning resources enable an exchange of practices that allow LRs to be found, adopted, and adapted.

Education setbacks because of the pandemic called for the development of locally developed materials for each region and division. Asio and Bayucca (2021) mentioned that schools were not yet ready for a distance learning scheme. The rescheduling of the school year and the shift to a mode of textual materials happened due to the physical and logistical issues caused by COVID-19. This pandemic is a disaster which threatens not only the lives of people but other aspects of living. Thus,

\footnotetext{
*Corresponding Author: Edward C. Jimenez: edward.jimenez@deped.gov.ph
} 
information, knowledge, awareness, and disaster programs should also be taken into consideration (Asio, 2021a, 2021b; Asio, 2020a, 2020b, 2020c) in dealing with a disaster just like this. Teachers, acting as the most important audio-visual LR of the education milieu, should be supported by quality assured and approved LRs that will suffice the continuity of lesson's flow within the specified targeted learning competency/ies for each lesson. Teachers' ICT skills are an essential and integral component of the development of learning resources (Bayucca, 2020a). Taking this into account, public school teachers were still able to sleep and perform their religious tasks (Asio \& Jimenez, 2021). The use of Alternative Delivery Mode (ADM) materials (e.g., self-learning modules, learning activity sheets, activity performance worksheets, etc.) both in elementary and secondary education is utilized by the entire country to supplement the lack of resources and titles delivered by the Central Office (CO). The provision of Most Essential Learning Competencies (MELCs) from the original learning competencies (LCs) was mapped, identified, and analyzed by the Bureau of Curriculum Development (BCD)-Curriculum Standards Development Division in collaboration with the Assessment Curriculum and Technology Research Centre (ACTRC), to develop learners' practical and lifelong skills for learning amidst a pandemic and to eventually attain a successful life (DepEd, 2020).

The lack of learning resources from the centrally developed LRs paved the way to the utilization of locally developed LRs in every division. The presence of learning resources from the CO became the main issue of all teachers and divisions in the Central Luzon Region due to lack of preparation time and the prohibition of physical contact which caused delays and insufficiencies of the ready to print learning resources. This situation tested the adversity capacity of school heads on which a study showed an above average result (Jimenez, 2021a) Considering these constraints, different School Division Offices (SDOs) have taken the initiative to encapsulate the development of locally developed learning resources within their area. As a result of such a daring move, certain contexts of professional skills (Asio \& Riego de Dios, 2018; 2019) and work ethics (Asio et al., 2019) among teachers, as well as supervisory rapport for administrators (Asio \& Jimenez, 2020), were enhanced. The development of locally development ADM learning resources underwent critical evaluation and quality assurance processes for the LRs to be utilized. However, due to lack of time and other resources in preparing the said LRs, the quality of the said materials has been compromised. The content, language, and layout design of the LRs suffered due to the rushed evaluation procedures as the opening of classes and time frame for the reproduction phase were on their way.

The evaluation process takes the procedure of looking at the social content and guidelines of the LRs to secure the credibility of the content of the materials. Based on the current status of LRs distributed to schools, feedback mechanisms were established through the error watch report, which found that most LRs have issues with content, intellectual property rights, plagiarism, language, and layout. Although the materials went through a stringent evaluation process, a lot of errors were still found by teachers, parents, and readers. This has brought the need to concretize the evaluation process framework to better serve its mandate and purpose as to the quality of LRs to be approved and utilized by the learners.

Despite all these, learners' declining interest in literature, particularly in reading, has been an obstacle in the process of shifting to the modular approach (Sebastian, 2019). Add this to the fact that teachers are still in the process of coping with the new normal of education. Teachers are left with uncertainties about the teaching and learning process amid the pandemic (Jimenez, 2021c). Capacity building to empower the potential Learning Resource Evaluators (LREs) must be continuous participation in various evaluation workshops of the agency concerning the quality assurance process and conformance review of LRs in all subject areas. 
Having considered all these, the researchers have crafted this study with the aim of giving light on the assessment of locally developed learning resources as a basis for empirical intervention programs. This paper is limited to the teachers and materials developed at the Schools Division Office in Central Luzon for the school year 2020-2021. This paper will utilize a mixed-method research design, particularly for the qualitative analysis and descriptive analysis. The survey instruments will also serve as the primary means of data gathering for the study. This research will also be used in formulating management intervention programs in assessing the ADM learning resources of the division.

\section{METHODOLOGY}

\subsection{Research Design}

In this study, qualitative research was employed. A qualitative research, according to Asio (2021), entails comprehension of a phenomena experienced by a person. The researcher employed a narrative-inquiry research design in this study. According to Creswell (2014), narrative-inquiry research is a humanities-form of inquiry in which the researcher examines the lives of individuals and invites one or more of them to share their experiences. The research approach is appropriate since the study includes stories from a variety of people.

\subsection{Participants of the Study}

30 Learning Resource (LR) Coordinators of elementary and secondary schools in a division in Central Luzon, Philippines for the school year 2020-2021. However, using a convenience sampling technique, the researcher only chose 10 based on the backgrounds of the informants. The inclusion criteria for the informants includes a Learning Resource (LR) Coordinator for at least a year or more and currently connected with the public schools. Listed below is the brief description of the informants (see Table 1). The researchers designated their labels or codes for the confidentiality and privacy of the participants in the study. They were labelled as LRC 1-10 randomly so that the researcher would maintain their anonymity.

Table 1. Participants of the Study

\begin{tabular}{ccc}
\hline Code Name & Sex & Public School \\
\hline LRC 1 & Female & Primary \\
LRC 2 & Female & Primary \\
LRC 3 & Female & Primary \\
LRC 4 & Female & Primary \\
LRC 5 & Female & Primary \\
LRC 6 & Female & Primary \\
LRC 7 & Male & Secondary \\
LRC 8 & Male & Secondary \\
LRC 9 & Female & Secondary \\
LRC 10 & Female & Integrated \\
\hline
\end{tabular}

\subsection{Data Gathering Procedure}

Before the conduct of the study, the researcher sought permission from the Schools Division Superintendent of the schools division. Upon receiving the approved permit, the researcher coordinated with the school heads (SHs) through phone or through the Messenger application 
program for the schedule of quantitative data collection. Due to the pandemic, the researcher collected narrative reports through Google Sheets. The confidentiality of the reports assures their security with anonymity. The data will be stored in the Learning Resource Management and Development Section (LRMDS) Office for filing and official business reference, while the transfer of it is prohibited unless for legal purposes. The procedure in the data collection was strictly followed by the researcher to secure the identity of the persons involved and the secrecy of information. The open-ended questionnaire was personally made by the researcher in accordance with the problems raised in the preceding chapter. This was asked during the phone call interview. A consent form was given to the respondents asking approval to record the interviews for documentation purposes.

\section{FINDINGS OF THE STUDY}

The aim of this paper is to explore the experiences of the Learning Resource Coordinators in the implementation of Alternative Delivery Mode (ADM) learning resources during the COVID-19 pandemic. Using a semi-structured questionnaire, the researcher extracted essential information for thematic analysis and presentation as presented below.

\subsection{The Significance of Learning Resources}

The learning resource is an important aspect of pedagogy since it guides teachers in their teaching to make it more interesting and appropriate for their learners regardless of their levels or age groups. Thus, in general, these learning resources are like small teaching manuals that will support teachers and learners in having fruitful and significant learning experiences for every subject matter covered in the subject course. Due to the pandemic, learning resources are even more in-demand and more challenging due to different dilemmas and obstacles that teachers and learners experience.

"The learning resources are very helpful during this pandemic. It serves as our springboard for online classes and a means of learning for modular pupils. Having a set of various learning resources enable us to cope with the struggle of online classes. Some of my colleagues in other province finding it difficult to continue teaching because they do not have any learning resources shared to them by their SDO." (LR Coordinator 1)

"The significance of learning resource for me is to assist teachers and learners to meet the expectations for learning. Before a learning is used in classroom or in teaching it must be evaluated and approved." (LR Coordinator 2)

"Learning Resources make our life easier as a teacher. It is where we can get what we needed in teaching. Now that it is beyond our reach because of technology, we can easily search what we are looking for through internet." (LR Coordinator 3)

"Learning resources are very useful as supporting tools in teaching and learning process. Learners can easily access the lessons by giving them learning resources such as worksheets, modules, video lessons etc. they can use these materials to enhance their knowledge and skills without the supervision of their instructor or teacher." (LR Coordinator 5)

"Learning resources are very important both for teachers and students. Teachers need additional learning resources that is ready and available to use as reference for their online classes or in making their self-learning materials. On the other hand, students who does not have access with the internet do need additional learning resources to help them in answering their modules and activity sheets." (LR Coordinator 8) 
"The learning resources are significant tools that can support learners' understanding of the different lessons as well as improve their academic achievement. In addition, these provide the learners flexibility since they can access, read and study them anytime they are free or available. Lastly, learners become independent learners, allowing them to explore the lessons with or without support from teachers or parents." (LR Coordinator 9)

"Learning resource is essential not only in gathering materials for the learnings of learners but most importantly in preparing and creating high quality materials which are beneficial for them." (LR Coordinator 10)

Looking at the many perspectives given by the informants, we can see that they all agree on one thing: learning materials are critical for instructors and students in a variety of ways. The informants highlighted numerous benefits and advantages for both instructors and learners, including a springboard for online classrooms, a form of help for teachers, and as a teaching support tool, among others. When it comes to learners, learning materials may be used to assess their requirements. It is also available at any time and from any location, and most of all, it aids learners in becoming selfsufficient in their learning and cultivates creativity. Learners' academic performance improves when they employ contextualized learning resources, particularly e-learning resources (Jimenez, 2020). Learner sourcing is gaining traction as a viable strategy for organizing the learner community and utilizing learners' intellect as developers of learning materials (Abdi et al., 2021).

\subsection{New Challenges, New Learning Resources, New Normal}

Challenges always come along the way especially in every new setting and in every innovation that every individual must face or experience. Learning resource production and dissemination is not spared. However, these challenges create a new opportunity to improve the delivery and service of teachers to learners. Although the process will be quite tricky and difficult, what prevails will be the will of teachers of continued learning among learners. Education is an agent of change towards the formation of the intended projection which requires education reform to meet the obligation with the compulsive detailed of information to achieve the goals of achieving the vision and mission towards academic excellence (Abdi et al., 2021).

"The printing of learning resources is one of the greatest challenges that we experienced at the beginning of the school year. Limited resources and fund in doing so is one of the factors that made it more challenging. Though we know that there will be printed modules that will be delivered but it will really take time on the processing and the classes can't wait. So, teachers took an initiative to look for donors and spend their weekends and holidays printing the learning resources. Luckily, our very dynamic LR Supervisor, suggested us to go on digitized modular approach. It did not ease the printing but greatly lessen the number of the printed materials that we need to do." (LR Coordinator 1)

"It is a big challenge for both, for teachers and learners. Because many challenges teachers face with distance learning are the result of asynchronous communication." (LR Coordinator 2)

"Technically speaking, the resources that the students needed are on tip of their fingers, it is just that not all (the learners) were able to access the internet. Mostly in our barangay, they do not have their own gadget. Reaching them thru technology is limited. We do receive printed copies from our Division 
32 E. C. Jimenez.: Experiences in the Application of Alternative Delivery Mode (ADM) Learning Resources during the Pandemic Period

Office but not all grade levels and subjects were given. It is also limited so we need to print it out." (LR Coordinator 3)

"Today in our new normal education some of the challenges that I encountered in terms of learning resources are having difficulty in retrieving the materials some of the parents did not return or get the materials on time because of their work. Another one is checking a lot of activity sheets and modules per week it is challenging but it is a great help for us teachers to see the progress of our learners." (LR Coordinator 5)

"Although there are plenty of resources on the internet, it is hard to find the right one that fits to what we need. You still must modify it. I notice that ready-made learning resources like video lessons per each MELC is not congruent with the activity sheets we have on hand, considering we are using the same MELCs as reference." (LR Coordinator 8)

"We, teachers, utilized all the available resources provided by our Schools Division Office. Besides, we also utilized the resources shared by the DepEd Central and Regional Offices. Our learners used the learning resources provided by the Schools Division Office. Besides, our School Head provided us with all the materials and equipment we need to print additional copies of modules and activity sheets, such as printer, ink and reams of bond paper. Therefore, in terms of learning resources during the new normal education, we encountered challenges, but we were able to resolve them with the support and guidance of our School Head." (LR Coordinator 9)

Different obstacles were found in the shared stories of the informants that follow. Printing, manufacturing, and availability of learning resources are among the obstacles, as are time restrictions, distribution, and the ways by which students do not have the capability to acquire or obtain their learning resources. Teachers' major concern in delivering learning resources in this situation is child protection to minimize infection and other unpleasant incidents (Asio et al., 2020; Bayucca, 2020). Simultaneously, instructors made every effort to utilise and exhaust all available resources for these learning tools. School leaders have a better understanding of what is going on with their constituents and students as a result of these shared experiences and views. According to Ivi (2019), a review of digital media reveals a set of distinct characteristics that, despite their many benefits, pose significant dangers to the brain's organization and functioning, as well as the learning process. As a result, the development of digital textbooks confronts a number of obstacles that current manufacturing has yet to overcome. This means that, through digital and blended learning techniques, schools should reinvent their processes to include a new paradigm of learning modalities to reduce the problems they face while also elevating the sense of learning among instructors and students (Jimenez, 2021c).

\subsection{Addressing error(s) and mistake (s) found in the learning materials}

Errors and mistakes are inevitable yet solvable aspects of any learning material. The causes vary from one factor to another since there is always a human tendency to commit one. In the educational process, errors are always present no matter how meticulous a teacher can be, especially in the preparation of learning resources. There will always be one minor error that will be committed (and sometimes this is normal). However, this small error might cause a huge controversy or issue. Nevertheless, this error (or errors) should be dealt with accordingly. 
"These minor errors are addressed at once by the teachers and relay at once to the parents. They change the instructions and choices if needed. Some misspelled words and typo-errors are recognized and relay to the learners. If a soft copy is available, they tried to edit it before printing." (LR Coordinator 1)

"Some parents would message me privately about the error, but I will also message it to the group to clarify the errors on that Modules. We also have this school-based error watch list report to be filled up by teachers who saw errors on the Activity Sheets, Modules and SLKs they used within the week. It was consolidated by the LR coordinator and submitted to Division Office - LRMDS email." (LR Coordinator 3)

"If we found minimal errors, we make sure to correct them before we give the ADM to our learners." (LR Coordinator 4)

"We scan the materials before printing and when we find some minimal errors, we reported it and immediately corrected. But sometimes if the material was already printed, we immediately informed the learners and parents regarding the errors." (LR Coordinator 5)

"We correct and explain the errors to students during online class. We give them additional reference and activities." (LR Coordinator 8)

"As an LR Coordinator, the first thing I did was to record it in the Error Watch Monthly Report. Afterward, I informed the incident to the Subject Coordinators for them to notify and advise the teachers to correct the errors found in the materials before distributing it to the learners." (LR Coordinator 10)

Based on the different standpoints that were shared by the informants of the study, there is a common thought that lingers amongst the different situations that the informants experienced: correct the mistake or error no matter how small or big it is. Of course, there is also proper protocol for reporting such errors to the head or coordinator, like an incident report for record purposes. Proper handling and assessment prior to distribution of learning resources are some steps that teachers and coordinators practice to avoid further errors in the future. Although error avoidance appears to be advantageous during learning and material growth, errorful learning followed by remedial feedback is beneficial to learning. It is advantageous when people are convinced that their errors are correct (Metcalfe, 2017). For many years, traditional printed textbooks served as a static medium for imparting knowledge to students. With the introduction of technology, numerous digital resources became available, prompting educational institutions to plan for the transition to e-books and other digital media. Printed and digital materials each have their own set of benefits and drawbacks (AlImamy, 2020).

\subsection{Impact of COVID-19 pandemic to learning resource management}

COVID-19 literally affects all aspects of human existence. Basically, it stopped the world's movement in terms of different aspects like economic, political, social, individual, and more importantly, educational. The education process came to a halt, but we people are tenacious and can adapt to this severe pandemic. Thus, the stoppage of learning is just temporary due to the immediate 
and appropriate responses and solutions of the world's brightest minds. Although schools are governed and need to follow the policies instituted by the IATF, many schools also set their own protocols for COVID-19 protection. With such action, the learning resources have some challenging impacts.

"Yes, because the learning resources are directed to the custodian and release at once to the teachers. Having said that, the learning resources printed by the SDO are divided to all the teachers and not confined in one room since there are also limited rooms. Teachers are using the rooms as well as their distribution and retrieval of materials. So, we asked the teachers to have a shelf where they can store the learning resources. Distribution of soft copy of learning resources went smoothly. We have a drive that is shared to all teachers where they can download learning materials and shared it to their digitized learners". (LR Coordinator 1)

"Yes, through the help of the authorities and parents we faced the challenges with a trust that this can we do it for the learners. It is always having an open communication both parents, learners and authorities to have a successful school year". (LR Coordinator 2)

"Yes. Since face to face is limited, we are not allowed to stay longer in school. We maximized our time in printing and sorting these materials. Retrieval of materials is also risky part. We want to make sure that the materials returned was in good condition but still we need to secure our health." (LR Coordinator 3)

"In our City Schools Division of Meycauayan, we had lots of learning resources aside from ADM from Region. Our hardworking LR Supervisor initiated us teachers to create our very own Learning Activity Sheets that would be a great help for our learners to study better even we are in distance learning mode." (LR Coordinator 4)

"Yes, our school were affected in terms management of learning resources because of COVID-19. In distributing and retrieving the materials we scheduled the parents every two weeks and ensure that they return all the materials in good condition." (LR Coordinator 5)

"Yes. This pandemic creates flexible teachers in providing different types of external learning resources, mostly from the internet. And some were being creative making their own LR based on their teaching approach and styles. This pandemic situation somehow makes a more progressive, adaptive teachers." (LR Coordinator 7)

"We are receiving plenty of self-learning materials and it consumes allot of space. Our shelves are full, and we do not have enough space to put the activity sheets and modules. To address this problem, teachers bought fruit crates and boxes where they can store and organize their activity sheets for safe keeping and for future use." (LR Coordinator 8)

"COVID-19 affected our school in the management of learning resources. Since our school adopted the Modular Distance Learning modality, both printed and digitized, we were not able to distribute the printed modules and learning activity sheets provided by the Schools Division office, as well as those we prepared during the ECQ and MECQ status in our province. For this reason, we were only able to send digitized copies to our learners, and only those who were able to download the digitized 
copies submitted their answer sheets and outputs on time. Those who opted for printed modular and failed to access the digitized copies had to wait until such time that we were allowed to go to school. This resulted to learners' late submission of answer sheets and outputs. ” (LR Coordinator 9)

"When the Pandemic happens, instructional materials such as ADM, SLK, SLM, SIMs and Learning Activity Sheets became more useful for the learners. Because of this, teachers with the guidance of the school heads and supervisors strive to provide quality materials appropriate for students' learning." (LR Coordinator 10)

Based on the accounts of the informants, there were again different opinions and experiences that were seen and shared. There were different struggles that informants experienced, like teachers' limited time in the school. At the same time, the distribution of the materials is also affected. Thus, collaboration with the barangay officials necessitates such action to reach out to learners. Some informants also see this situation as an opportunity to explore other means and measures to make sure that the learning process continues no matter what. For example, the pandemic cultivated creativity and innovation among teachers so that their learning resources will have an impact on the learners even if there is a pandemic. Teachers' mental health has become an attribute of all school leaders to remain healthy (physically, socially, psychologically, and socially) as a result of the pandemic, and has been proven to have a major influence on teachers' learning resource development (Jimenez, 2021a). To make learning and teaching interesting and engaging, teachers have the option to create and develop extra activities as well as document the outcomes of sessions (McLeod, 2020). This suggests that in the face of a pandemic, instructors must be knowledgeable of a wide range of issues.

\subsection{Improvements and innovations on Alternative Delivery Mode (ADM) of Learning Resources}

Suggestions and recommendations for improvement in any form or way are important aspects of improvement, especially in the ADM learning resources. In this way, these resources will adapt constantly and appropriately to the changing tides of time and situations where it is necessary to conform. Although it may instill challenges along the way, nevertheless, our teachers and learners will always find time and opportunities that will guide them to success, no matter how difficult the situation is. The same goes to the institution and the heads that will supervise such innovative ideas and concepts. "We can further improve it since there are some AS that have contents that are repeated lesson and has same activities on it". (LR Coordinator 1)

"We know that the budgets were limited. Having 1:1 ratio for ADM learning resources produced by the Division Office is impossible. Also, we cannot deny the fact that there were errors in the modules. We cannot blame the writers, the editors and evaluators for their shortcomings. Let us just support one another and be thankful that despite this pandemic, education continues." (LR Coordinator 3)

"Some ADM learning resources like activity sheets arrived late, so we weren't able to give them to students and have to print our own. Other activity sheets like in TLE, does not fit with the offered specialization in our school." (LR Coordinator 8)

“The ADM learning resources are supplementary materials that aim to enhance students' learning, particularly those who have no gadget and/or internet connection. Therefore, we are thankful that 
the Schools Division Office provided us sufficient ADM learning resources for our learners." (LR

Coordinator 9)

As seen from the experiences shared by the LR coordinators, there are some important points, issues and concerns that were delineated from their inputs, like problems in the budgetary department. Materials were scarce during the COVID-19 pandemic. They are difficult to procure and, at the same time, do not reach areas where they are necessary. Another issue that was raised is the delayed arrival of the learning resources, which are considered very important since learners will also submit their requirements late as well, which will again hamper the teachers in checking and recording their achievements. Thus, these issues need to be dealt with accordingly. Leaders and policymakers have difficult decisions ahead to balance the budget, maintain school services, and prioritize safety amid the COVID-19. School financing is still in flux, and if the economy does not improve fast, k-12 schools may face substantial cuts (Lafortune et al., 2020). In light of the funding requirements for the procurement of learning resources, Section 3 (a) of Republic Act No. 9184, also known as "The Government Procurement Reform Act," states that "transparency in the procurement process and in the implementation of procurement contracts through wide dissemination of bid opportunities and participation of relevant non-government organizations, wherein the procurement follows the bidding process, which requires a minimum number of days, thereafter.

Figure 1.

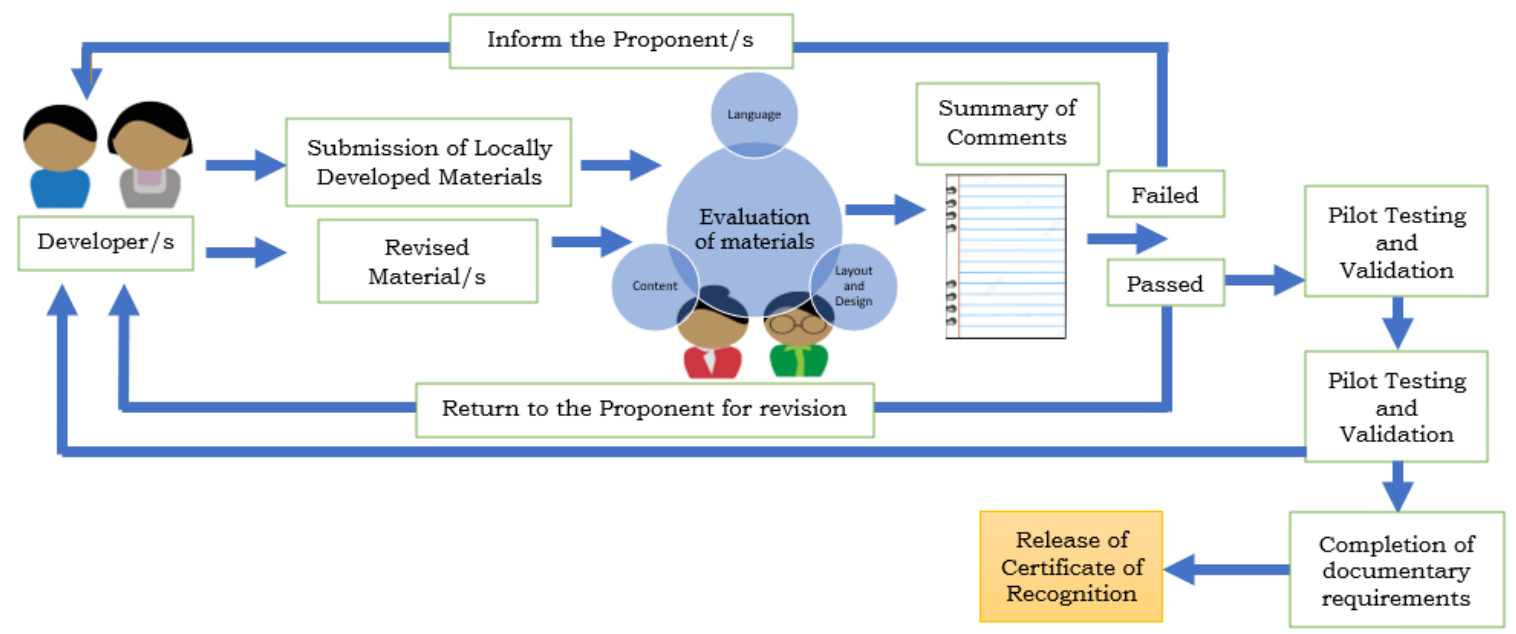

Figure 1. Flowchart of ADM Learning Resource Evaluation Process

As can be seen from the diagram, it shows the empirical intervention program of the Learning Resource Management and Development Section (LRMDS) Division Quality Assurance Team (DQAT) in performing the evaluation process of ADM Learning Resources. This simply means that the DQAT will adapt and provide a concrete, comprehensive, and detailed process for assuring the credibility, reliability, and accountability of the LRs to be used by the learners.

\section{CONCLUSION}

Based on the findings of the qualitative analysis in the study, the researcher therefore concludes that the experiences shared by the Learning Resource Coordinators varied from one perspective to another. Based on the thematic analysis, the Alternative Delivery Mode (ADM), according to the informants, is significant for them in their teaching and learning of the students. However, there were new challenges in the implementation of the ADM, such as poor internet connectivity, printing of materials, and miscommunication, to name a few. Nevertheless, the teachers still persisted and 
exhausted all the necessary resources and efforts so that the learning materials would reach all the learners. Also, teachers were not spared from mistakes and errors. Therefore, correcting them on time was definitely and appropriately. The COVID-19 pandemic brought about great changes in the management of learning resources for the coordinators as well as the teachers. And finally, there is always room for improvement in the implementation of ADM by every coordinator out there. The comments and suggestions create innovation and practical approaches and solutions for the coming years.

\section{Recommendations}

In the light of the conclusions drawn, the following recommendations are hereby offered by the researcher:

1) LR Coordinators, together with the School Property Custodians, should maintain a high level of proper care and storage of the ADM materials for reuse in the next school year.

2) Teachers are encouraged to make modifications (as necessary) to the ADM Learning Resources provided by the SDO to better serve their learners in different aspects and levels.

3) School heads should include strategic forecasting in the latest survey of the learning modalities to prepare for the number of materials needed to be provided for every grade level.

4) Education Program Supervisors should have constant coordination with all subject coordinators to address the modifications, corrections, and issues concerning their subject area's ADM Learning Resources for proper dissemination and guidance.

5) Education Program Supervisors can use this study as a springboard to develop their programs and adapt this strategy for the development of learning resources anchored by higher-order thinking skills content or activity-lesson-assessment (ALA) for improved academic performance of learners.

6) Further studies to strengthen and develop the concept of ADM for future generation.

\section{REFERENCES}

[1] Abdi, S., Khosravi, H., Sadiq, S., \& Demartini, G. (2021). Evaluating the quality of learning resources: A learner sourcing approach. IEEE Transactions on Learning Technologies, 14(1), 81-92. https://doi.org/10.1109/TLT.2021.3058644.

[2] Al-Imamy, S. Y. (2020). Blending printed texts with digital resources through augmented reality interaction. Education and Information Technologies, 25(4), 2561-2576. https://doi.org/10.1007/s10639019-10070-w.

[3] Asio, J. M. R. (2021a). Disaster Awareness and Level of Compliance to Disaster Programs in a Highly Urbanized City. Aquademia, 5(1), ep21003. https://doi.org/10.21601/aquademia/9581.

[4] Asio, J. M. R. (2021b). Sources of Information, Training Needs, Preparation and Response to Disaster of Selected Communities in Central Luzon, Philippines. International Journal of Humanities, Management and Social Science, 4(1), 30-38. https://doi.org/10.36079/lamintang.ij-humass-0401.226

[5] Asio, J.M.R. (2021c). Research designs in the new normal: A brief overview. Academia Letters, Article 2596. https://doi.org/10.20935/AL2596.

[6] Asio. J. M. R. (2020a). Disaster Knowledge and Household Preparations of Selected Communities in Central Luzon, Philippines: Basis for Enhanced Community Disaster Education Program. International Journal of Humanities, Management and Social Sciences, 3(2), 44-51. https://doi.org/10.36079/lamintang.ij-humass-0302.127. 
[7] Asio, J. M. R. (2020b). Disaster management program compliance and problems encountered in two provinces in Central Luzon, Philippines. Interdisciplinary Research Review, 15(5), 24 - 31. https://ph02.tcithaijo.org/index.php/jtir/article/view/240805.

[8] Asio, J.M.R. (2020c). Natural calamity, its impact and level of preparations: Significance and implications to the community. Disaster Advances, $22-30$. https://papers.ssrn.com/sol3/papers.cfm?abstract_id=3718496

[9]Asio, J. M. R., \& Bayucca, S. A. (2021). Spearheading education during the COVID-19 rife: Administrators' level of digital competence and schools' readiness on distance learning. Journal of Pedagogical Sociology and Psychology, 3(1), 19-26. https://doi.org/10.33902/JPSP.2021364728

[10] Asio, J. M. R., \& Jimenez, E. C. (2021). Teachers' Sleep, Religious Task, and Suicidal Thoughts: A Preliminary Assessment. International Journal of Multidisciplinary: Applied Business and Education Research 2 (1), 71 - 79. http://doi.dx.org/10.11594/ijmaber.02.01.02.

[11] Asio, J.M.R., \& Jimenez, E.C. (2020). Professional development, organizational climate, supervisory rapport and overall satisfaction of employees: An attitudinal study. International Journal of Scientific $\begin{array}{llll}\text { Research in } \quad \text { Multidisciplinary } & \text { Studies, }\end{array}$ https://papers.ssrn.com/sol3/papers.cfm?abstract_id=3624812

[12] Asio, J. M.R., Bayucca, S. A., \& Jimenez, E. C. (2020). Child protection policy awareness of teachers and responsiveness of the school: Their relationship and implications. Shanlax International Journal of Education, 9(1), 1-10. https://doi.org/10.34293/education.v9i1.3384

[13] Asio, J. M. R., \& Riego de Dios, E. E. (2019). The college students' perspective on what makes an educator well-qualified. Journal of Pedagogical Research, 3(3), 126-138. https://doi.org/10.33902/jpr.v3i3.124.

[14] Asio, J.M.R., Riego de Dios, E.E., \& Lapuz, A.M.E. (2019). Professional skills and work ethics of selected faculty in a local college. PAFTE Research Journal, 9(1), 164-180. https://papers.ssrn.com/sol3/papers.cfm?abstract_id=3452971.

[15]Asio, J.M.R., \& Riego de Dios, E.E. (2018). $21^{\text {st }}$ century attributes and skills of a teacher in the perspective of college students. https://files.eric.ed.gov/fulltext/ED594675.pdf

[16] Bayucca S. A. (2020a). Teachers' Information and Communication Technology Skills Assessment: Basis for a Comprehensive ICT Training Program. International Journal of Education, Science, Technology and Engineering, 3(2): 85-93. DOI: 10.36079/lamintang.ijeste-0302.160

[17]Bayucca, S.A. (2020b). Teachers' Awareness and School's Responsiveness to the Child Protection Policy: Basis for a Development Plan. International Journal of Academic Multidisciplinary Research, 4(6), 59-65. https://papers.ssrn.com/sol3/papers.cfm?abstract_id=3640895

[18]Department of Education (2020). DO 018, s. 2020 - Policy Guidelines for the Provision of Learning Resources in the Implementation of the Basic Education Continuity Plan | Department of Education. Deped.Gov.Ph, 1-6. https://www.deped.gov.ph/2020/07/20/july-20-2020-do-018-s-2020-policyguidelines-for-the-provision-of-learning-resources-in-the-implementation-of-the-basic-educationcontinuity-plan/

[19] Ivić, I. (2019). Printed and digital media: Printed and digital textbooks. Center for Educational Policy Studies Journal, 9(3), 25-49. https://doi.org/10.26529/cepsj.694

[20] Jimenez, E. C. (2020). Contextualized E-Learning Resource: A Tool for Stronger Academic Platform. International Journal of Case Studies in Business, IT, and Education, 4(2), 110-116. http://doi.org/10.5281/zenodo.4018344.

[21] Jimenez, E. C. (2021a). Adversity and emotional quotients of public elementary school heads amidst the COVID-19. International Journal of Didactical Studies, 2(2), 101460. https://doi.org/10.33902/IJODS.2021269755

[22] Jimenez, E. C. (2021b). Impact of Mental Health and Stress Level of Teachers to Learning Resource Development. Shanlax International Journal of Education, 9(2), 1-11. https://doi.org/10.34293/education.v9i2.3702

[23] Jimenez, E. C. (2021c). Project NEW NORMAL-Navigating Electronic World to Numerous Online Resources of Modality Approaches in Learning. International Journal of Multidisciplinary: Applied Business and Education Research, 2(1), 134-140. https://doi.org/10.11594/ijmaber.02.01.09 
[24] Lafortune, J., Mehlotra, R., \& Paluch, J. (2020). Funding California Schools When Budgets Fall Short. Public Policy Institute of California, https://www.ppic.org/wp-content/uploads/funding-california-schoolswhen-budgets-fall-short-october-2020.pdf

[25] Libbrecht, P. (2015). Adaptations to a Learning Resource. Acta Didactica Napocensia, 8(1), 67-74.

[26] McLeod, R. L. (2020). Diversity Awareness for K-6 Teachers: The Impact on Student Learning. Rowman \& Littlefield Education, https://eric.ed.gov/?id=ED522985.

[27] Metcalfe, J. (2017). Learning from Errors. Annual Review of Psychology, 68, 465-489. https://doi.org/10.1146/annurev-psych-010416-044022

[28] Sebastian, M. F. DC. (2019). Using Songs as Springboard to Teaching Poetry and Narratives for Improved Comprehension. International Journal of Academic and Applied Research, 4(6), 72-78, https://doi.org/10.13140/RG.2.2.18420.58242 